\title{
Nonbullous cutaneous pemphigoid: a systematic review
}

\author{
Lamberts A, Meijer JM, Jonkman MF \\ University of Groningen, University Medical Center Groningen, Department of Dermatology, \\ Center for Blistering Diseases, Groningen, the Netherlands
}

\section{Conclusions}

- Nonbullous cutaneous pemphigoid presented with erythematous, urticarial plaques in $52.3 \%$ and papules/nodules in $20.5 \%$ of the cases. Mucosal involvement was reported in one case.

- Long mean diagnostic delay of 22.6 months.

- The majority of the cases $(90.2 \%)$ did not develop blisters during follow-up.

- Pruritus $(100 \%)$ at high age (mean 74.9 years) may be a clinical clue.

Clinicians should consider DIF and immune serological tests in elderly with chronic itch.

\section{Introduction and Objectives}

Cutaneous pemphigoid, also known as bullous pemphigoid (BP), typically presents with tense blisters that arise on erythematous, urticarial plaques, and is accompanied by severe pruritus. However, $20 \%$ of the patients do not have blisters at the time of diagnosis, called nonbullous cutaneous pemphigoid. The absence of blistering can make the recognition of this disease difficult for clinicians and can result in a delay of diagnosis.

Aim: To characterize nonbullous cutaneous pemphigoid

\section{Results}

39 articles presenting 132 cases were included. Demographics of the reported cases are shown in table 1. Figure 2 shows the timeline of delay in diagnosis and blister formation. The efflorescences described are displayed in table 2. Lesions were most frequently located on the extremities $(67.2 \%)$ and the trunk (65.6\%). Table 3 shows the reported laboratory results in nonbullous cutaneous pemphigoid cases.

Histopathological findings were most frequently non-specific: perivascular infiltrate in $60.4 \%$ and non-specific findings not further specified in $26.4 \%$. Eosinophils were present in $47.2 \%$ and neutrophils in $13.2 \%$. In $15.1 \%$ of the cases a microscopic subepidermal split was reported.

Table 1. Demographics of the reported nonbullous cutaneous pemphigoid cases

\begin{tabular}{llc}
\hline Demographic outcome measurements & $\begin{array}{c}\text { Reported in } \\
\text { no. of cases }\end{array}$ \\
\hline Mean age at presentation, in years & 74.9 & 78 \\
\hline Male cases & $33(42.3 \%)$ & 78 \\
\hline Cases experiencing itch & $77(100 \%)$ & 77 \\
\hline Cases with mucosal involvement & $1(7.1 \%)$ & 14 \\
\hline Cases with blister development after diagnosis & $13(9.8 \%)$ & 132 \\
\hline Mean total follow-up, in months & 19.6 & 46 \\
\hline
\end{tabular}

\section{Methods}

The EMBASE and MEDLINE databases were searched using 'nonbullous cutaneous pemphigoid' and various synonyms. There were no limitations on article type. Language was limited to Dutch, German or English. All articles reporting on one or multiple cases of nonbullous cutaneous pemphigoid were included. The references of all included articles were checked for missing articles. Cases were excluded if blisters were described before or at the time of diagnosis. (figure 1).
Figure 1. Sudy selection flow diagram

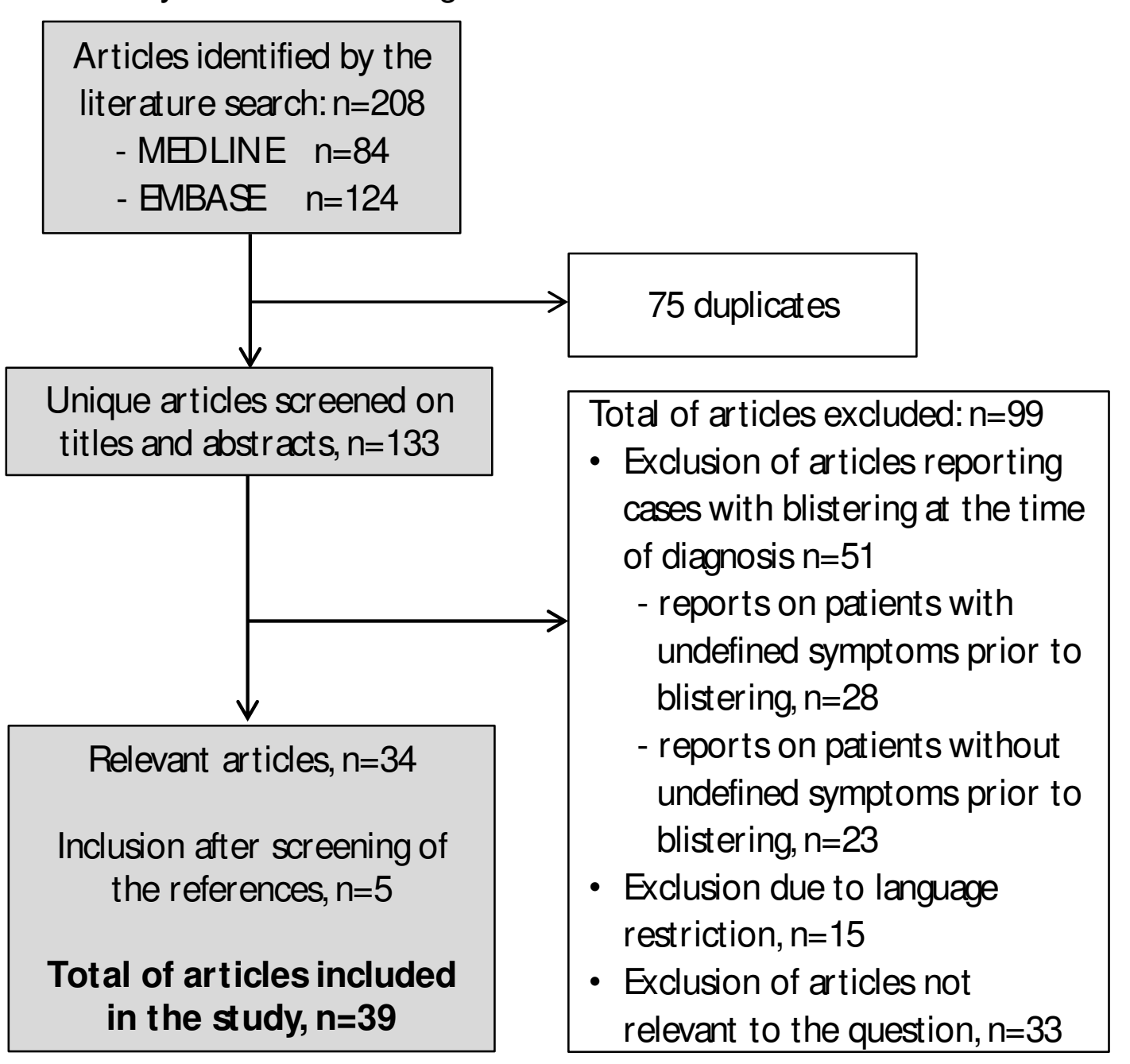

Figure 2. Delay in diagnosis Duration of blister formation

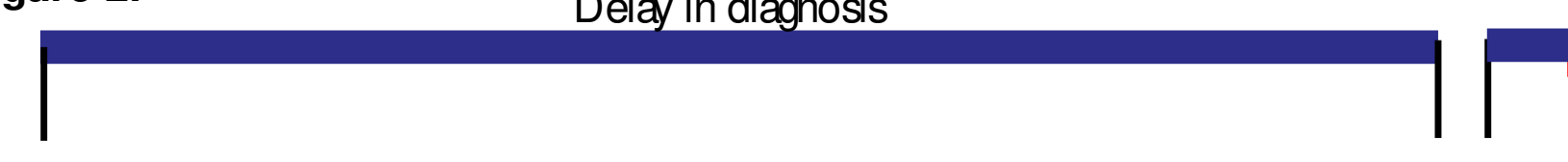

Start of symptoms

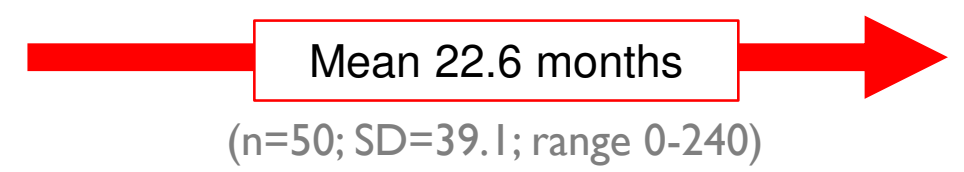

Diagnosis nonbullous cutaneous pemphigoid $n=132$

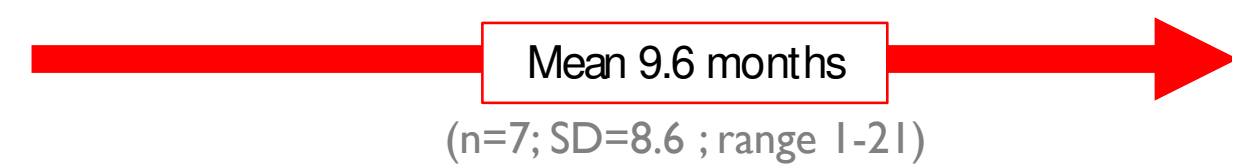

Blistering $n=13$
Table 2. Skin efflorescences reported

\begin{tabular}{ll}
\hline Efflorescences & N o. of cases (\%) \\
\hline Erythematous, urticarial plaques & $69(52.3 \%)$ \\
\hline Papules/nodules & $27(20.5 \%)$ \\
\hline Eczematous lesions & $16(12.1 \%)$ \\
\hline No primary lesions reported & $6(4.5 \%)$ \\
\hline Dermatitis herpetiformis-like lesions & $5(3.8 \%)$ \\
\hline Ulcerations & $3(2.3 \%)$ \\
\hline Erythroderma & $3(2.3 \%)$ \\
\hline Other: - Scarring alopecia & $1(0.8 \%)$ \\
$\quad$ - Vegetations & $1(0.8 \%)$ \\
$\quad$ - Solitary macule & $1(0.8 \%)$ \\
\hline Excoriations & $30(22.7 \%)$ \\
\hline * all 6 casespresented with secondary lesions in the form of excoriations
\end{tabular}

* all 6 cases presented with secondary lesions in the form of excoriations
Table 3. Reported laboratory findings

\begin{tabular}{lcc}
\hline Laboratory test & $\begin{array}{c}\text { No. of cases with } \\
\text { positive test results(\%) }\end{array}$ & $\begin{array}{c}\text { Reported in } \\
\text { no. cases }\end{array}$ \\
\hline $\begin{array}{l}\text { DIF microscopy, linear IgG and/or } \\
\text { C3c depositions along the BMZ }\end{array}$ & $123(93.2 \%)$ & 132 \\
\hline IIF*, IgG & $42(76.4 \%)$ & 55 \\
\hline IIF on salt split skin, IgG, epidermal binding & $46(90.2 \%)$ & 51 \\
\hline Nc16a 日ISA, IgG & $15(57.7 \%)$ & 26 \\
\hline BP230 EISA, IgG & $10(52.6 \%)$ & 19 \\
\hline Immunoblot BP180, IgG & $11(32.4 \%)$ & 34 \\
\hline Immunoblot BP230, IgG & $20(55.6 \%)$ & 36 \\
\hline${ }^{*}$ Different substrates were used by different authors & &
\end{tabular}

